\title{
Small Ionic Radius Limits Magnesium Water Interaction in Amorphous Calcium/Magnesium Carbonates
}

\author{
Anders C. S. Jensen, Silvia Imberti, Wouter J.E.M. Habraken, and Luca Bertinetti* \\ Cite This: J. Phys. Chem. C 2020, 124, 6141-6144 \\ Read Online
}

ABSTRACT: The stabilizing effect of magnesium ions on amorphous calcium carbonate has been studied extensively due to its widespread occurrence in biogenic minerals. It has long been suggested that magnesium binds water more strongly compared to calcium given its relatively high dehydration energy. However, recent work has shown that mobility increases in the presence of a magnesium ion relative to the pure calcium phase. Using total scattering and EPSR modeling, we show here that in amorphous magnesium carbonate, because of the small size of the ion, the coordination number of magnesium is smaller and the interaction with water are therefore limited. As a result, $\sim 35 \%$ of water molecules are bound exclusively by hydrogen bonds mainly to the anions.

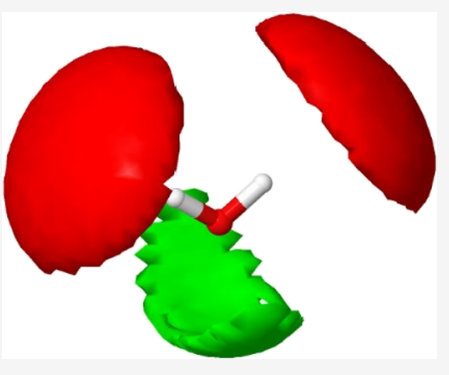

\section{INTRODUCTION}

Magnesium has long been examined as an additive in calcium carbonates, generally studied for its stabilizer effect on the amorphous phase $\mathrm{e}^{1-4}$ but is also found as an additive in, for example, biogenic calcium carbonates. ${ }^{5-7}$ Magnesium ions are well-known to increase the lifetime of the amorphous phase ${ }^{1,8}$ and even control the polymorph selection during crystallization. ${ }^{9}$

The stabilizing effect has long been thought to originate in the relatively high dehydration energy of $\mathrm{Mg}^{2+}$ compared to $\mathrm{Ca}^{2+}$, arguing that magnesium ions bind water more strongly, thereby reducing mobility of the ions. ${ }^{10,11}$ However, recent studies have shown that diffusion of water is significantly faster in amorphous magnesium carbonate (AMC) compared to amorphous calcium carbonate (ACC) and even compared to mixed phases (amorphous calcium magnesium carbonate, $\mathrm{ACMC})$ with as much as $73 \% \mathrm{Mg} /(\mathrm{Ca}+\mathrm{Mg})$, suggesting that calcium reduces water mobility more effectively than magnesium, despite the lower dehydration energy. ${ }^{2,12}$ It has also been shown that magnesium incorporates a much larger portion of hydroxide ions into the amorphous carbonate phase compared to calcium, which provides additional stabilization. ${ }^{2,13,14}$

To better understand how the cation interact with water, more detailed structural understanding is needed and while the structure of ACC has been discussed for over a decade, ${ }^{15-18}$ only limited number of studies address the local structure in $\mathrm{AMC}^{19}$ and even fewer have addressed the mixed phase. ${ }^{20}$

To better understand the role of water and the local coordination in AMC and mixed calcium/magnesium carbonate, X-ray and neutron total scattering were used together with empirical potential structural refinement (EPSR). The general stoichiometry of the systems considered in this work can be expressed as
$\mathrm{Ca}_{1-x} \mathrm{Mg}_{x}\left(\mathrm{CO}_{3}\right)_{1-0.32 x}(\mathrm{OH})_{x 0.64} \cdot \mathrm{nH}_{2} \mathrm{O}$ as described in our previous work..$^{2}$ We find that for $x=1$, that is, for AMC, the low coordination number of magnesium limits the number of water molecules that can bind to the cation as most of the sites are occupied by the anions, resulting in $\sim 35 \%$ of the water only bound by hydrogen bonds. In the mixed phase $(x=0.5$, ACMC) the magnesium ion showed a similar local structure to the one in AMC, but here, the calcium ion binds more water molecules, and therefore, the amount of water not binding to cations is reduced to $\sim 10 \%$. This explains the faster diffusion of water in the AMC phase with respect to ACC and ACMC and suggests that the stabilizing effect of magnesium is more likely connected to the presence of the hydroxide ion rather than the strong cation-water interaction.

\section{EXPERIMENTAL SECTION}

Materials synthesis: AMC/ACMC was synthesized and characterized as reported previously. ${ }^{2}$ Samples were made by rapid mixing of a $20 \mathrm{~mL} 1 \mathrm{M}(\mathrm{Ca} / \mathrm{Mg}) \mathrm{Cl}_{2}\left(\mathrm{CaCl}_{2} \cdot 2 \mathrm{H}_{2} \mathrm{O} \geq\right.$ $99 \%, \mathrm{MgCl}_{2} \cdot 6 \mathrm{H}_{2} \mathrm{O}=99-102 \%$, Sigma Aldrich) solution with $480 \mathrm{~mL} \mathrm{Na} \mathrm{CO}_{3}\left(\mathrm{Na}_{2} \mathrm{CO}_{3} \cdot 10 \mathrm{H}_{2} \mathrm{O}=99.999 \%\right.$, Sigma Aldrich $)$ to get an initial concentration of $40 \mathrm{mM}$ of both the carbonate and the $\mathrm{Ca} / \mathrm{Mg}$ ion. The solution was filtered, after which the solid was washed with cold ethanol (99.8\%, Sigma Aldrich) and dried in a vacuum desiccator for a minimum of $24 \mathrm{~h}$ to remove any excess ethanol. Incoherent inelastic neutron scattering (IINS): IINS was performed at the TOSCA ${ }^{28}$

Received: December 16, 2019

Revised: February 28, 2020

Published: February 28, 2020 
instrument at ISIS (STFC Rutherford Appleton Laboratory, Didcot, UK). Samples were mounted in aluminum cans and sealed with indium wire. Samples were cooled to $<30 \mathrm{~K}$ before measuring and kept at $\sim 10 \mathrm{~K}$ during the measurement. FTIR: FTIR-ATR was performed on a Nicolet IS5 (Thermo Fisher scientific, Waltham, MA, US) with an ID5 ATR module. Spectra were measured from 550 to $4000 \mathrm{~cm}^{-1}$ and averaged over 64 spectra. Pair distribution function (pdf) measurement and analysis: X-ray pdf was measured at I15 at the diamond light source (Didcot, UK) using a $0.16 \AA$ beam and a Perkin Elmer detector. Neutron pdf was measured at the SANDALS Instrument $^{29}$ at ISIS (STFC Rutherford Appleton Laboratory, Didcot, UK). Each sample was measured for $\sim 8 \mathrm{~h}$. Data reduction for both $\mathrm{X}$-ray and neutron measurements was performed in Gudrun. ${ }^{30} \mathrm{He}$ Pycnometry: Pycnometer measurement was performed on an Ultrapycnometer 1200e MUPY-31-T (Quantachrome Instruments, Boynton Beach, Florida, US). Approximately $1 \mathrm{~g}$ was placed in a $\sim 4 \mathrm{~mL}$ sample holder and measured using $\mathrm{He}$ gas. Five measurements were averaged for the final result.

\section{RESULTS AND DISCUSSION}

Using TGA, ICP and FTIR/IINS (Figure S1) the sample composition was determined to be $\mathrm{Ca}_{1-x} \mathrm{Mg}_{x}\left(\mathrm{CO}_{3}\right)_{1-0.32(4) x}(\mathrm{OH})_{x 0.64(8)} \cdot \mathrm{nH}_{2} \mathrm{O}$ as reported in our previous study, with $n$ defined as the number of water molecules relative to the number of cations (i.e., calcium and magnesium). ${ }^{2}$ To investigate the effect of the different cations on the interactions of water with ions and to describe the local structure within the amorphous carbonates, samples with two different compositions were chosen, each with two hydration levels $(n=1.1-1.2$ and $n=0.5-0.7)$ : the pure magnesium phase $(x=1)$ and the $50 / 50$ mixed phase $(x=0.5)$. To present a complete picture of the structural effects within the full compositional range $(0<x 1)$, we compared the results obtained here with those previously reported on the pure calcium phase $(x=0)$ exhibiting equivalent hydration levels. ${ }^{21}$ To examine the local structure, $\mathrm{X}$-ray and neutron pair distribution function (pdf) was conducted together with EPSR $^{22,23}$ using the mentioned composition and experimentally determined the density as the input together with Lennard-Jones reference potentials (Tables S1 and S2). ${ }^{21,24,25}$ Details about the simulation procedure are given in the Supporting Information. The neutron and X-ray pdf allows for the histogram of interatomic distance to be experimentally determined (Figure 1B,D) from which the local structure can be assessed using EPSR. Because the molecular moieties of the system studied contain common atoms ( $\mathrm{O}$ and $\mathrm{H}$ ), in the following, the oxygens and hydrogens will be distinguished by the $c, h$, and $w$ subscripts when belonging to carbonate, hydroxide, and water respectively. Figure 1 shows the EPSR fit to both the structure factor $(\mathrm{S}(\mathrm{Q}))$ and the pdf $(\mathrm{g}(\mathrm{r}))$. The agreement between data and the model is remarkable over the whole $\mathrm{Q}$ range, except at low $\mathrm{Q}$ in the neutron data, likely caused by the inelastic correction, which is problematic in this region.

The EPSR model allows for a deconvolution of the pdf into the individual partial pair distribution functions (PPDF, Figures S2-S4) from which the coordination spheres can be determined by the first peak at low $r$ and used to determine the coordination number and the angular distribution of $\mathrm{O}$ around the cations (Figure 2, Tables S3 and S4). In the pure magnesium phase, an average of 5.0 oxygens $\left(2.9 \mathrm{O}_{c}+1.3 \mathrm{O}_{h}+\right.$
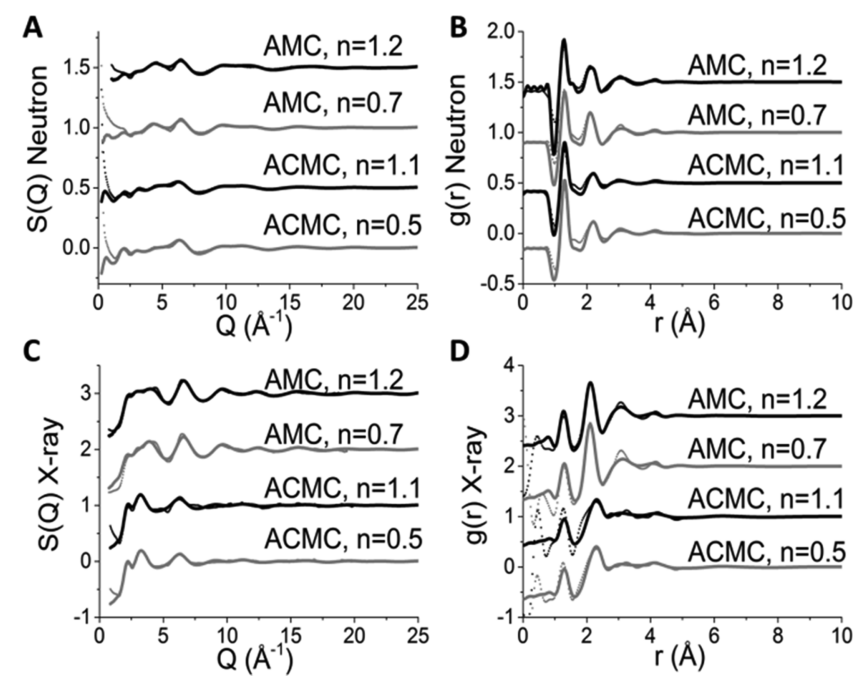

Figure 1. EPSR fit (lines) of the total scattering data (dots) measured with (A, B) neutrons and (C, D) X-rays for AMC and ACMC for both $n=0.5-0.7$ (grey) and fully hydrated $n=1.1-1.2$ (black) with $n$ $=\mathrm{H}_{2} \mathrm{O} /(\mathrm{Mg}+\mathrm{Ca})$.

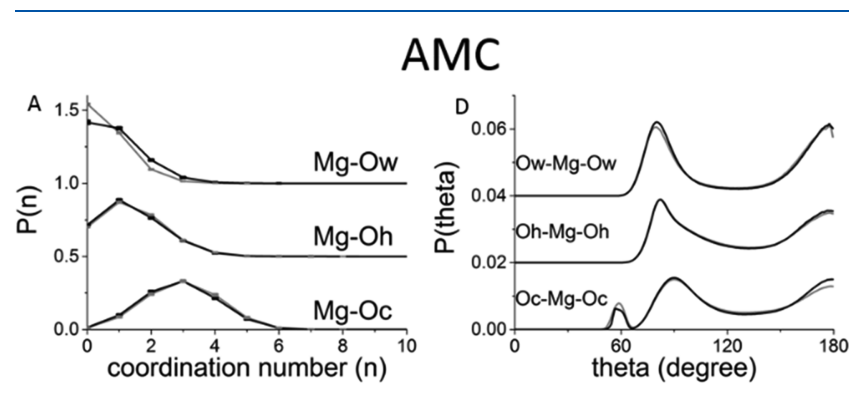

$\mathrm{ACMC}$
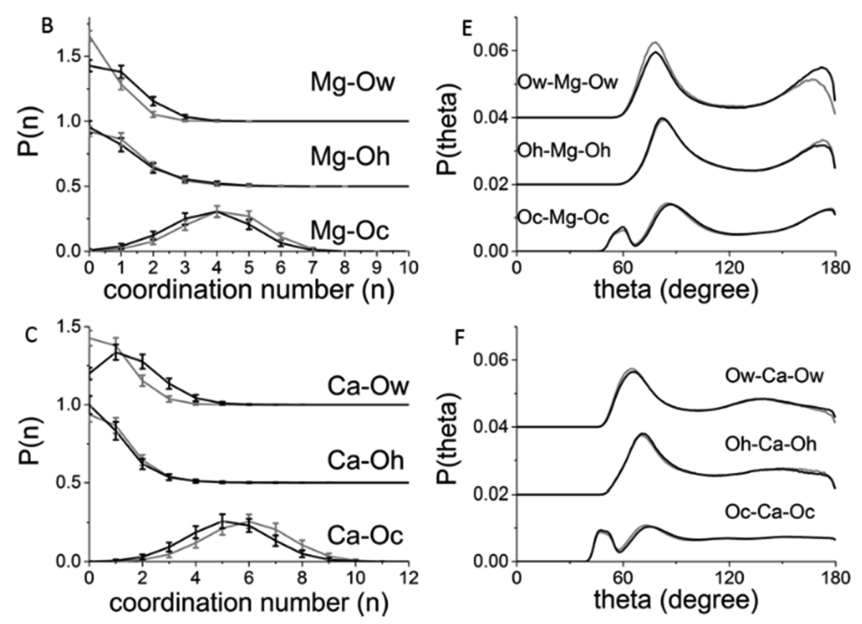

Figure 2. Distribution of coordination number for $\mathrm{O}$ around $\mathrm{Mg}$ in (A) AMC, (B) ACMC, and (C) around Ca in ACMC in the first coordination sphere for $\mathrm{O}_{c}, \mathrm{O}_{h}$, and $\mathrm{O}_{w}$. Distribution of angles between two oxygen coordinating to the same metal ion in (D) AMC and (E, F) ACMC. $\mathrm{O}_{c}$ : oxygen from $\mathrm{CO}_{3}{ }^{2-}, \mathrm{O}_{h}$ : oxygen from $\mathrm{OH}^{-}$, $\mathrm{O}_{w}$ : oxygen from $\mathrm{H}_{2} \mathrm{O}$. The two hydration levels are shown in grey $(n$ $=0.5-0.7)$ and black $(1.1-1.2)$.

$0.8 \mathrm{O}_{w}$ ) coordinating directly to the cation are observed, with almost no change upon dehydration (Figure 2A and Table S3). In the mixed phase, the local environment around magnesium exhibits a lower hydroxide content relative to carbonate ions with a mean of 5.4, directly coordinating oxygens $\left(3.7 \mathrm{O}_{c}+\right.$ 
$\left.0.9 \mathrm{O}_{h}+0.8 \mathrm{O}_{w}\right)$. Only a minor decrease in the number of coordinating water molecules upon dehydration can be observed. Similar to the pure calcium phase, ${ }^{21}$ in the mixed phase, an average of 7.4 oxygens $\left(5.2 \mathrm{O}_{c}+0.7 \mathrm{O}_{h}+1.5 \mathrm{O}_{w}\right)$ are directly coordinating the calcium ion (Figure $2 \mathrm{C}$ and Table S4). With respect to the hydrated mixed phase, the average number of $\mathrm{O}_{w}$ decreases by $0.7, \mathrm{O}_{c}$ increases by 0.7 upon dehydration, and no change is observed in the number of $\mathrm{O}_{h}$. This trend is also represented in the distribution of coordination numbers (Figure $2 \mathrm{~A}-\mathrm{C}$ ), which shows a general preference for cation-carbonate binding, as expected, given the large number of $\mathrm{O}_{c}$ present in the sample. Additionally, a higher number of water molecules are observed binding to the calcium ion compared to the magnesium ion, while the number of hydroxide ion binding to each ion is comparable. The lack of change in the coordination number for AMC can be explained by a large population (35\%) of the water not coordinating to any magnesium ions, which is reduced to $23 \%$ after dehydration. This is also evident in the mixed phase where the majority of the water is removed from the calcium ions (Figure $2 \mathrm{C}$ ), although here, only $\sim 10 \%$ of the water molecules are not coordinating to a cation, similar to ACC. ${ }^{21}$ Additionally, the local environment around magnesium is more crowded as seen by the angular distribution (Figure 2E,F) where two peaks are seen at 90 and $180^{\circ}$, suggesting a predominantly octahedral coordination. In contrast, the calcium ion shows no preferential coordination angles to oxygens, except the nearest neighbor angle of $65-75^{\circ}$ and only a weak at $140^{\circ}$ peak in the angle between $\mathrm{O}_{w}$, as also observed in ACC. ${ }^{21}$ The well-ordered coordination sphere around magnesium suggests that the small size of magnesium, and hence, the smaller volume of the first coordination sphere limits the number of atoms that can be arranged around it, forcing the oxygen atoms to adopt the octahedral coordination. Combining this with the coordination number distribution (Figure 2A,B) suggests that magnesium favors binding the anions over the water molecules, resulting in the larger population of unbound water in the absence of calcium. Unlike magnesium, the calcium ions in the mixed phase do not show any preferential coordination, suggesting that it can adopt multiple different local environments as observed in the pure calcium phase and for calcium in the aqueous solution. ${ }^{21,26}$ This could explain the slower water diffusion observed in the mixed phase $(x=0.73)$ compared to the pure magnesium phase as the calcium is free to change its local coordination to accommodate the water molecules that would otherwise only interact via weaker hydrogen bonding to the anions.

In all the samples, we observe extensive hydrogen bonding as observed by the peak at $\sim 1.8 \AA$ in the PPDFs of the $\mathrm{O}-\mathrm{H}$ pairs (Figures S2 and S3), showing that all the oxygen and hydrogen types are hydrogen bond acceptors and donors, respectively. The most prominent peak is observed in pairs with $\mathrm{O}_{c}, \mathrm{O}_{h}$, and $\mathrm{H}_{w}$, and the most probable spatial orientation is shown in Figure 3. The models also show that all water molecules bind to at least one anion via hydrogen bonding. The additional $\mathrm{H}_{h} \cdots \mathrm{O}_{w}$ hydrogen bond may also facilitate the high population of water not binding to the cation as the $\mathrm{H}_{h}$ binds to the same site as the magnesium ions (Figure 3). Despite the large portion of water molecules not interacting with the cation in AMC, no water percolation ${ }^{27}$ were observed; instead, the water molecules favor water-anion hydrogen bonding over water-water hydrogen bonding, consistent with the IINS spectrum (Figure S1D), showing strong similarity

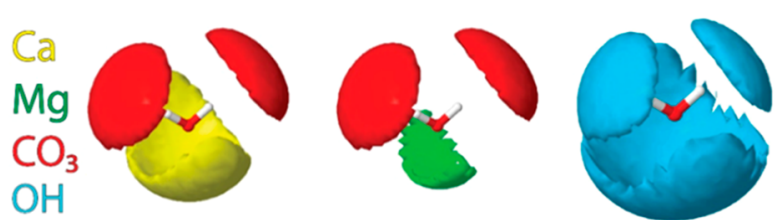

Figure 3. Spatial density function showing the hydroxide, carbonate, calcium, and magnesium ions in the local water environment in the mixed phase. The remaining spatial density functions are shown in Figures S5-S7.

with the spectrum for ACC. ${ }^{21}$ In the mixed phase, the low population of non-cation-coordinating water $(\sim 10 \%)$ suggests that there is a preference to coordinate cations over hydrogen bond formation with the hydroxide ions in the presence of the calcium ions.

\section{CONCLUSIONS}

The combination of neutron and X-ray total scattering with EPSR fitting has shown that magnesium, in amorphous carbonates, despite binding water more strongly than calcium, exhibits a tight coordination structure that limits the number of water molecules binding to the cation. As a result, roughly a third of water molecules in the pure AMC phase are bound exclusively by hydrogen bonds to other water molecules and anions. However, in the mixed phase, only $\sim 10 \%$ of water are not directly binding to the cations, as a larger amount of water molecules is bound to calcium. This is likely due to the larger size of the calcium ion, which results in a looser and more dynamic coordination sphere around calcium with respect to the one around magnesium. As a consequence, more water is bound to cations in ACC and ACMC. This suggests that the relatively fast diffusion of water observed in AMC, compared to the mixed phase with up to $73 \%$ calcium, ${ }^{2,12}$ is a result of the weaker binding through hydrogen bonds of around a third of the water molecules.

\section{ASSOCIATED CONTENT}

\section{SI Supporting Information}

The Supporting Information is available free of charge at https://pubs.acs.org/doi/10.1021/acs.jpcc.9b11594.

FTIR, TGA, and IINS spectra; EPSR initial parameters; and all PPDFs derived for all samples along with coordination number for an extensive number of coordination shells (PDF)

\section{AUTHOR INFORMATION}

\section{Corresponding Author}

Luca Bertinetti - Max Planck Institute of Colloids and Interfaces, Potsdam 14424, Germany; 10 orcid.org/00000002-4666-9610; Email: luca.bertinetti@mpikg.mpg.de

\section{Authors}

Anders C. S. Jensen - Max Planck Institute of Colloids and Interfaces, Potsdam 14424, Germany; School of Physics and Astronomy, Queen Mary University of London, London E1 4NS, United Kingdom; Department of Chemical Engineering, Imperial College London, London E1 4NS, United Kingdom; (1) orcid.org/0000-0003-2366-6051

Silvia Imberti - STFC, Rutherford Appleton Laboratory, ISIS Pulsed Neutron and Muon Source, Didcot OX11 OQX, U.K.; (1) orcid.org/0000-0001-7037-6829 
Wouter J.E.M. Habraken - Max Planck Institute of Colloids and Interfaces, Potsdam 14424, Germany

Complete contact information is available at:

https://pubs.acs.org/10.1021/acs.jpcc.9b11594

\section{Notes}

The authors declare no competing financial interest.

\section{ACKNOWLEDGMENTS}

We would like to thank ISIS for the allocation of beam time at the TOSCA and SANDALS instruments, under the grant numbers RB1520242 and RB1520182, Dr. Stewart Parker for the support with the IINS measurements, Ms. Jeannette Steffen for the support with ICP measurements, and Prof. Peter Fratzl for valuable discussion in the preparation of this manuscript.

\section{REFERENCES}

(1) Rodriguez-Blanco, J. D.; Shaw, S.; Bots, P.; Roncal-Herrero, T.; Benning, L. G. The role of $\mathrm{pH}$ and $\mathrm{Mg}$ on the stability and crystallization of amorphous calcium carbonate. J. Alloys Compd. 2012, 536, S477-S479.

(2) Jensen, A. C. S.; Rodriguez, I.; Habraken, W. J. E. M.; Fratzl, P.; Bertinetti, L. Mobility of hydrous species in amorphous calcium/ magnesium carbonates. Phys. Chem. Chem. Phys. 2018, 20, 1968219688.

(3) Wolf, S. L. P.; Jähme, K.; Gebauer, D. Synergy of $\mathrm{Mg}^{2+}$ and poly(aspartic acid) in additive-controlled calcium carbonate precipitation. CrystEngComm 2015, 6857.

(4) Han, Y.-J.; Wysocki, L. M.; Thanawala, M. S.; Siegrist, T.; Aizenberg, J. Template-Dependent Morphogenesis of Oriented Calcite Crystals in the Presence of Magnesium Ions. Angew. Chem., Int. Ed. 2005, 44, 2386-2390.

(5) Robach, J. S.; Stock, S. R.; Veis, A. Mapping of magnesium and of different protein fragments in sea urchin teeth via secondary ion mass spectroscopy. J. Struct. Biol. 2006, 155, 87-95.

(6) Addadi, L.; Raz, S.; Weiner, S. Taking Advantage of Disorder: Amorphous Calcium Carbonate and Its Roles in Biomineralization. Adv. Mater. 2003, 15, 959-970.

(7) Weiner, S.; Levi-Kalisman, Y.; Raz, S.; Addadi, L. Biologically Formed Amorphous Calcium Carbonate. Connect. Tissue Res. 2003, 44, 214-218.

(8) Rodriguez-Blanco, J. D.; Shaw, S.; Bots, P.; Roncal-Herrero, T.; Benning, L. G. The role of $\mathrm{Mg}$ in the crystallization of monohydrocalcite. Geochim. Cosmochim. Acta 2014, 127, 204-220.

(9) Nishiyama, R.; Munemoto, T.; Fukushi, K. Formation condition of monohydrocalcite from $\mathrm{CaCl}_{2}-\mathrm{MgCl}_{2}-\mathrm{Na}_{2} \mathrm{CO}_{3}$ solutions. Geochim. Cosmochim. Acta 2013, 100, 217-231.

(10) Politi, Y.; Batchelor, D. R.; Zaslansky, P.; Chmelka, B. F.; Weaver, J. C.; Sagi, I.; Weiner, S.; Addadi, L. Role of Magnesium Ion in the Stabilization of Biogenic Amorphous Calcium Carbonate: A Structure-Function Investigation. Chem. Mater. 2010, 22, 161-166.

(11) Lippmann, F. Sedimentary Carbonate Minerals; Springer Science \& Business Media, 2012, Vol. 6.

(12) Koishi, A.; Fernandez-Martinez, A.; Ruta, B.; Jimenez-Ruiz, M.; Poloni, R.; di Tommaso, D.; Zontone, F.; Waychunas, G. A.; MontesHernandez, G. Role of Impurities in the Kinetic Persistence of Amorphous Calcium Carbonate: A Nanoscopic Dynamics View. J. Phys. Chem. C 2018, 122, 16983-16991.

(13) Leukel, S.; Mondeshki, M.; Tremel, W. Hydrogen Bonding in Amorphous Alkaline Earth Carbonates. Inorg. Chem. 2018, 57, 11289-11298.

(14) Tobler, D. J.; Rodriguez Blanco, J. D.; Sørensen, H. O.; Stipp, S. L. S.; Dideriksen, K. Effect of $\mathrm{pH}$ on Amorphous Calcium Carbonate Structure and Transformation. Cryst. Growth Des. 2016, $16,4500-4508$.
(15) Cartwright, J. H. E.; Checa, A. G.; Gale, J. D.; Gebauer, D.; Sainz-Díaz, C. I. Calcium Carbonate Polyamorphism and Its Role in Biomineralization: How Many Amorphous Calcium Carbonates Are There? Angew. Chem., Int. Ed. 2012, 51, 11960-11970.

(16) Gebauer, D.; Gunawidjaja, P. N.; Ko, J. Y. P.; Bacsik, Z.; Aziz, B.; Liu, L.; Hu, Y.; Bergström, L.; Tai, C.-W.; Sham, T.-K.; Edén, M.; Hedin, N. Proto-Calcite and Proto-Vaterite in Amorphous Calcium Carbonates. Angew. Chem., Int. Ed. 2010, 122, 9073-9075.

(17) Fernandez-Martinez, A.; Kalkan, B.; Clark, S. M.; Waychunas, G. A. Pressure-Induced Polyamorphism and Formation of 'Aragonitic' Amorphous Calcium Carbonate. Angew. Chem., Int. Ed. 2013, 52, 8354-8357.

(18) Michel, F. M.; MacDonald, J.; Feng, J.; Phillips, B. L.; Ehm, L.; Tarabrella, C.; Parise, J. B.; Reeder, R. J. Structural Characteristics of Synthetic Amorphous Calcium Carbonate. Chem. Mater. 2008, 20, 4720-4728.

(19) White, C. E.; Henson, N. J.; Daemen, L. L.; Hartl, M.; Page, K. Uncovering the True Atomic Structure of Disordered Materials: The Structure of a Hydrated Amorphous Magnesium Carbonate $\left(\mathrm{MgCO}_{3}\right.$. $\left.3 \mathrm{D}_{2} \mathrm{O}\right)$. Chem. Mater. 2014, 26, 2693-2702.

(20) Radha, A. V.; Fernandez-Martinez, A.; Hu, Y.; Jun, Y.-S.; Waychunas, G. A.; Navrotsky, A. Energetic and structural studies of amorphous $\mathrm{Ca}_{1-\mathrm{x}} \mathrm{Mg}_{\mathrm{x}} \mathrm{CO}_{3} \cdot \mathrm{nH}_{2} \mathrm{O}(0 \leqslant \mathrm{x} \leqslant 1)$. Geochim. Cosmochim. Acta 2012, 90, 83-95.

(21) Jensen, A. C. S.; Imberti, S.; Parker, S. F.; Schneck, E.; Politi, Y.; Fratzl, P.; Bertinetti, L.; Habraken, W. J. E. M. Hydrogen Bonding in Amorphous Calcium Carbonate and Molecular Reorientation Induced by Dehydration. J. Phys. Chem. C 2018, 3591.

(22) Soper, A. K. Partial Structure Factors From Disordered Materials Diffraction Data: An Approach Using Empirical Potential Structure Refinement. Phys. Rev. B 2005, 72, 104204.

(23) Soper, A. K. Computer Simulation as a Tool for the Interpretation of Total Scattering Data from Glasses and Liquids. Mol. Simul. 2012, 38, 1171-1185.

(24) Bruni, F.; Imberti, S.; Mancinelli, R.; Ricci, M. A. Aqueous Solutions of Divalent Chlorides: Ions Hydration Shell and Water Structure. J. Chem. Phys. 2012, 136, No. 064520.

(25) Imberti, S.; Botti, A.; Bruni, F.; Cappa, G.; Ricci, M. A.; Soper, A. K. Ions in water: The microscopic structure of concentrated hydroxide solutions. J. Chem. Phys. 2005, 122, 194509.

(26) Ikeda, T.; Boero, M.; Terakura, K. Hydration properties of magnesium and calcium ions from constrained first principles molecular dynamics. J. Chem. Phys. 2007, 127, No. 074503.

(27) Goodwin, A. L.; Michel, F. M.; Phillips, B. L.; Keen, D. A.; Dove, M. T.; Reeder, R. J. Nanoporous Structure and Medium-Range Order in Synthetic Amorphous Calcium Carbonate. Chem. Mater. 2010, 22, 3197-3205.

(28) Stewart, F. P.; Felix, F.-A.; Anibal, J. R.-C.; John, T.; Svemir, R.; Roberto, S. P.; Giuseppe, G.; Fernández, C. J. Recent and Future Developments on TOSCA at ISIS. J. Phys.: Conf. Ser. 2014, 554, No. 012003.

(29) Benmore, C.; Soper, A. The SANDALS Manual. A Guide to Performing Experiments on the Small Angle Neutron Diffractometer for Amorphous and Liquid Samples at ISIS; Council for the Central Lab. of the Research Councils (CLRC): 1998.

(30) Soper, A. RAL Technical Report RAL-TR-2011-013 2011. 